\title{
Evolución jurídica de la responsabilidad del Estado por actos terroristas en Colombia
}

\author{
Legal evolution of State responsibility \\ for terrorist acts in Colombia
}

DOI: http://dx.doi.org/10.17981/juridcuc.13.1.2017.4

Artículo de revisión. Fecha de recepción: 03/08/2017 Fecha de aceptación: 14/09/2017

\author{
Jaime Camilo Bermejo Galán ${ }^{1}$ \\ Simón Bolívar (Colombia) \\ jaimecamilob@hotmail.com
}
Oscar David Galán Escalante ${ }^{2}$
Simón Bolívar (Colombia)
oscardavidgalan@hotmail.com

\section{Juan José lamadrid González ${ }^{3}$ \\ Simón Bolívar (Colombia) juanjlamadrid@hotmail.com}

Para citar este artículo:

Bermejo, J. (2017). Evolución jurídica de la responsabilidad del Estado por actos terroristas en Colombia. JURÍDICAS CUC, vol. 13, no. 1, pp. 71-96. DOI: http://dx.doi.org/10.17981/ juridcuc.13.1.2017.4

\section{Resumen}

La evolución del precedente judicial del Consejo de Estado frente al tema de la responsabilidad extracontractual del Estado colombiano por actos terroristas ha venido decantando unas pautas que se deben tener en cuenta para poder determinar o imputarle responsabilidad al Estado en los eventos en que un ente Estatal omite la advertencia o la prevención de una amenaza de un acto terrorista, o cuando pone en riesgo a la población donde se encuentra asentada una base militar que es declarada objetivo de los grupos ilegales terroristas, generando así una falla del servicio en la protección de la población o colocándola en riesgo, lo cual no está obligada a soportar.

\footnotetext{
${ }^{1}$ Abogado; Doctor en Ciencias Política; Magíster en Derecho Administrativo, especialista en Derecho Constitucional y docente universitario.

${ }^{2}$ Abogado egresado de la Universidad Libre.

${ }^{3}$ Abogado egresado de la Universidad Libre.
}

${ }^{-}$The author; licensee Universidad de la Costa - CUC. JURÍDICAS CUC vol. 13 no. 1, pp. 71-96. Enero - Diciembre, 2017 Barranquilla. ISSN 1692-3030 Impreso, ISSN 2389-7716 Online 
El objetivo del presente trabajo consiste en determinar, con fundamento en la jurisprudencia del Consejo de Estado, cuándo el Estado colombiano está en el deber jurídico de indemnizar a las personas cuando han sufrido un daño a causa de un atentado terrorista. Se parte de los antecedentes a nivel internacional acerca del objeto de estudio y se realiza un estudio de las principales sentencias del Consejo de Estado acerca de responsabilidad estatal por este tipo de actos, para el desarrollo del mismo se utilizara el método deductivo en razón de que se iniciará la investigación de los conceptos generales de la de la responsabilidad extracontractual del Estado y los diferentes títulos de imputación de responsabilidad estatal, aplicándolos de manera especial frente a actos terroristas. Como conclusión, se establece que en Colombia, muy a pesar de que existe un campo normativo mediante el cual las víctimas de terrorismo pueden solicitar alguna indemnización o compensación, es la jurisdicción contenciosa administrativa a la que las víctimas prefieren acudir y así obtener una reparación integral a sus daños ocasionados por un acto terrorista que el Estado debió evitar.

\section{Palabras claves}

Daño, Estado, jurisprudencia, responsabilidad, terrorismo.

\section{Abstract}

The evolution of the Judicial Precedent of the Council of State, regarding the issue of the non-contractual liability of the Colombian State for terrorist acts, has been setting some guidelines which must be taken into account in order to determine or impute liability to the State, in the events in which a State entity omits the warning or prevention of a threat of a terrorist act, or when it puts at risk the population where a military base is established that is declared objective of the illegal terrorist groups, generating to itself a failure of the service in the protection of the population or placing it at risk which it is not obliged to bear. The objective of the present work is to determine, based on the jurisprudence of the State Council, when the Colombian State has the legal duty to compensate people when they have suffered damage due to a terrorist attack, starting from the antecedents to international level about the object of study and conducting a study of the main decisions of the State Council on state responsibility for this type of acts, for the development of the same will be used the deductive method because of the initiation of investigation of the concepts general of the State's non-contractual liability and the different titles of attribution of state responsibility, applying them in a special way against terrorist acts. 
As a conclusion, it is established that in Colombia, despite the fact that there is a normative field through which victims of terrorism can claim some compensation or compensation, it is the administrative contentious jurisdiction that the victims prefer to go and thus obtain a comprehensive reparation to their damages caused by a terrorist act that the State had to avoid

Keywords

Damage, State, Jurisprudence, Responsibility, Terrorism.

\section{INTRODUCCIÓN}

Como es natural, en un país sumergido en confrontaciones con grupos al margen de la ley, organizaciones de narcotraficantes, delincuencia común, etc. durante medio siglo, los altos índices de violencia y la feroz guerra que ha sostenido el Estado colombiano contra los diferentes grupos alzados en armas, hacen del terrorismo un fenómeno que supera los límites soportables de inseguridad e incertidumbre. Además de lo anterior, la situación económica del país, el desempleo y demás flagelos que aquejan a nuestra nación no han permitido que el legislador desarrolle políticas de solidaridad suficientes para indemnizar por esta vía integralmente a los perjudicados por los actos terroristas (elespectador.com, 2017).

El Comité Internacional de la Cruz Roja - CICR (2011) ha considerado que los actos terroristas son "los actos o las amenazas de violencia cuya finalidad sea aterrorizar a la población civil, prohibición esta que es considerada norma de derecho consuetudinario tanto para conflictos armados internacionales, como para conflictos armados no internacionales", de este modo se ve reflejado el concepto que tienen los órganos internacionales relacionados con los actos terroristas.

Estos actos causan perjuicios morales y patrimoniales a las personas, que por supuesto deben ser reparados. Este escenario ha causado diferentes puntos de vista en cuanto a la existencia o no de la responsabilidad del Estado colombiano, por ende, cabe desatacar la evolución del precedente ju- 
dicial por parte del Consejo de Estado colombiano, donde se han establecido unas pautas para endosarle una responsabilidad de tipo patrimonial al Estado, como lo son en los casos de riesgo excepcional y la falla del servicio. Este último cuando un ente estatal omite la advertencia de los particulares o la prevención de una amenaza de un acto terrorista. La teoría del riesgo excepcional ocurre cuando hay ataques dirigidos a elementos representativos del Estado o funcionarios estratégicos del mismo, colocando al particular en una situación de riesgo creado de manera consciente por el Estado que se torna excepcional y, que en caso de realizarse y causarse un daño, desborda los parámetros bajo los cuales está desarrollado el principio de igualdad frente a las cargas públicas, es el caso del transeúnte que pasa precisamente por el lugar (elemento representativo del Estado) en el momento justo en que se perpetró el ataque; situación que también corresponde al grupo de habitantes aledaños a una zona o lugar definido como de riesgo.

Motivo por el cual, a través de la vía jurisdiccional, las personas o sus familiares afectadas por este daño antijurídico pueden lograr de algún modo que el daño ocasionado por actos terroristas les sea reparado. Es así como el operador judicial en materia de lo Contencioso Administrativo juega un papel importante para que los administrados que resulten afectados, damnificados o lesionados con este hecho tengan claros los presupuestos que deben cumplir con la finalidad de lograr una indemnización económica por esta vía. Basados en lo establecido en el artículo 90 de la Constitución, "El Estado responderá patrimonialmente por los daños antijurídicos que le sean imputables, causados por la acción o la omisión de las autoridades públicas. En el evento de ser condenado el Estado a la reparación patrimonial de uno de tales daños, que haya sido consecuencia de la conducta dolosa o gravemente culposa de un agente suyo, aquél deberá repetir contra éste", y la evolución jurisprudencial que se ha surgido en esa materia, aclarando que algunos perjuicios causados por actos terroristas no son imputables a la Administración. 
En el desarrollo de este artículo se hará énfasis en unos elementos comunes que permitirán abarcar de forma analítica la situación actual de la doctrina y la jurisprudencia del Consejo de Estado basados en los sistemas de responsabilidad administrativa (falla en el servicio, riesgo excepcional y daño especial) que han servido de instrumentos para logar determinar la responsabilidad del Estado y la indemnización de las víctimas por estos hechos o actos terroristas.

\section{Antecedentes históricos de la responsabilidad extracontractual del Estado}

Si se parte de los antecedentes de la evolución de la jurisdicción de lo contencioso administrativo, se debe resaltar el surgimiento de la responsabilidad del Estado desde la aparición de fallos surgidos en el derecho francés, como lo es L'arrêt Blanc, fallo que incrusta en el ordenamiento jurídico la primera responsabilidad del Estado por falla del servicio, y así surge el principio de igualdad frente a las cargas públicas y la teoría del riesgo. Sin embargo, el doctrinarte Javier Tamayo Jaramillo (2000) considera que en Francia no está consagrado el régimen de responsabilidad del Estado por actos terroristas, y que, por el contrario, lo que existe son sistemas de indemnización basados en principios de solidaridad social. En este sentido, y con los golpes que ha recibido la sociedad y el Estado francés por actos terroristas consumados por el Estado Islámico, se prevé que su jurisprudencia realizará un giro a favor de los administrados.

El doctrinante y profesor Ricardo de Ángel Yágüez sostiene que la indemnización en Francia por actos terroristas "se lleva a cabo por medio de un fondo de garantía (creado sobre el modelo del fondo de accidentes de circulación), que se financia por medio de un impuesto que grava todas las pólizas de seguro sobre la propiedad". La indemnización se concede a todo aquel que, cualquiera que sea su nacionalidad, es víctima de actos de terrorismo en suelo francés, e incluso a los ciudadanos franceses en el extranjero, siempre que se hubiesen registrado ante las oficinas consulares. 
Se considera que una posición tan rígida como la anterior pretende proteger el patrimonio público, también logra ser excesivamente desconocedora de los derechos de las víctimas en aquellos casos donde se genere la falla del servicio ante una advertencia de la comunidad o ante circunstancias lo suficientemente evidentes de un acto terrorista como para hacer previsible a las autoridades la inminencia del ataque. Ante situaciones como las anteriores, frente a las cuales se realiza el riesgo precisamente porque el Estado no tomó las medidas necesarias para repeler, menguar o evitar un acto terrorista, no basta una mera indemnización a título de solidaridad social del Estado, es preciso desarrollar un régimen de responsabilidad patrimonial del Estado edificado en la falla del servicio.

La evolución de la responsabilidad extracontractual del Estado colombiano desde el punto de vista normativo se parte o divide en dos escenarios trascendentales, como lo son: antes de la expedición de la constitución del 1991 y después de la expedición de ésta. En la primera, la responsabilidad extracontractual del Estado se había desarrollado vía jurisprudencial, por ende, en el periodo comprendido entre la segunda mitad del siglo XIX y el año de 1964, lapso en donde la competencia para conocer las demandas contra el Estado por responsabilidad extracontractual estaba atribuida a la Corte Suprema de Justicia, Sala de Casación Civil y de Negocios Generales, en virtud de la cláusula general de competencia (Tamayo, 2000, p. 7).

Durante el siglo XIX, el Estado colombiano aún mantenía una marcada tendencia a defender la irresponsabilidad del Estado por sus actuaciones frente a los particulares. La Corte Suprema de Justicia sólo consideraba que el Estado debía responder cuando así lo consagrara específicamente alguna norma jurídica, es decir, la regla general era la irresponsabilidad del Estado y la excepción era la responsabilidad por mandato legal expreso. Era claro entonces, que la labor del juez se limitaba a la aplicación exegética de las normas, y que, por ello, no encontraba ningún precepto que lo llevara a aplicar al Estado 
las reglas de responsabilidad mucho más amplias que ya existían en ese entonces para determinar la responsabilidad civil de los particulares.

No obstante, a finales de ese siglo, surgen las primeras providencias que superan el anterior pensamiento, aplicando, además, los principios generales del Código Civil a las actuaciones de la Administración. El primer intento de establecer unos criterios generales de responsabilidad del Estado consistió en la aplicación de la teoría de la responsabilidad indirecta, consagrada en los artículos 2347 y 2349 del Código Civil.

Posteriormente, la Corte Suprema de Justicia comenzó a dar aplicación al artículo 2341 del Código Civil (Ley 57, 1887) "El que ha cometido un delito o culpa, que ha inferido daño a otro, es obligado a la indemnización, sin perjuicio de la pena principal que la ley imponga por la culpa o el delito cometido", con el que se dedujo responsabilidad directa para los miembros del sector estatal que ocupaban un cargo representativo dentro de la Administración. Tanto esta norma como las referentes a la responsabilidad indirecta, que se aplicaba a los funcionarios auxiliares, implicaron en su momento la necesidad para el perjudicado de probar los cuatro elementos de la responsabilidad civil, a saber: acción u omisión, culpa, daño y nexo causal entre la actuación culposa y el daño ocasionado.

Adicionalmente, la Corte Suprema comenzó a atenuar la carga probatoria para los particulares al aplicar analógicamente la responsabilidad con culpa presunta consagrada en el artículo 2356 del Código Civil, especialmente frente a los casos de actividades peligrosas realizadas por la Administración y deduciendo excepcionalmente responsabilidad del Estado con base en la teoría de la falla del servicio, en la cual se fijaba la atención en el cumplimiento de la función estatal frente a los particulares antes que la actuación culposa de determinado funcionario, el fundamento jurídico para la aplicación de este régimen se encontró en el artículo 16 de la Constitución Nacional de 1886. 
En 1964, el Decreto 528 implanta un importante cambio en materia de responsabilidad extracontractual del Estado al atribuir al Consejo de Estado la competencia general para conocer de los casos que tuvieran por origen una actuación de la Administración, es así como uno de los primeros fallos que se puede resaltar es la sentencia del 29 de julio de 1947 promovida por el diario El Siglo. En ella se estableció claramente que la responsabilidad encontrada se había derivado de los principios consagrados en el Código Contencioso Administrativo y en la Constitución Política mas no en la normatividad civil para condenar al Estado a indemnizar los perjuicios ocasionados con una actuación lícita de la Policía Nacional. Por primera vez se acudió a la equidad, plasmada en el principio de igualdad frente a las cargas públicas, según el cual nadie está obligado a soportar más perjuicios que el resto de la comunidad por causa de una actuación que supuestamente beneficia a toda la sociedad (República de Colombia. Corte Constitucional. 1947)

En principio se alcanzaron a tratar bajo este régimen los casos de daños causados con ocasión de actividades peligrosas originadas por la función estatal. En estos procesos se presumía la falla del servicio cuando el particular probaba la existencia de una actividad peligrosa y el daño causado como consecuencia de aquella, paralelamente, se seguían manejando los tres regímenes de responsabilidad sin falla que había aplicado la mencionada corporación antes de 1964, es decir, la responsabilidad por perjuicios ocasionados por la ocupación de inmuebles por trabajos públicos, la derivada de almacenaje de mercancías en bodegas oficiales y a la originada por daño especial.

Con la expedición de la Constitución del 1991 y la consagración del artículo 90, el juez administrativo comienza a contar con un soporte constitucional explícito para cimentar la jurisprudencia en materia de responsabilidad del Estado.

Es así como surgen nuevas fuentes de la responsabilidad extracontractual del Estado, que comprenden: la falla del servicio, expropiación y ocupación de inmuebles en caso de gue- 
rra, el daño especial, el riesgo excepcional, el enriquecimiento injusto, la función legislativa, la función jurisdiccional, etc. De esta forma, se establece un nuevo concepto frente a la responsabilidad patrimonial del Estado en la medida que el verdadero y auténtico fundamento de la responsabilidad patrimonial está en el deber que tiene éste de proteger y garantizar la efectividad de los derechos a sus administrados, los cuales no pueden ser vulnerados en sus derechos o patrimonio, alterando la igualdad de todos los ciudadanos frente a las cargas públicas, efectos estos que los hace antijurídicos en sí mismos.

La jurisprudencia contenciosa administrativa, con ocasión de la expedición de la nueva Constitución y la influencia por la doctrina española, fundamenta la responsabilidad estatal en el daño antijurídico como aquella lesión de un interés legítimo, patrimonial o extrapatrimonial que la víctima no está en la obligación de soportar. Este concepto ha permitido cambiar el punto de vista desde el cual se mira la antijuridicidad en un determinado caso, pues antes aquella se analizaba con respecto a la actuación de la Administración y ahora se mira desde la óptica del perjudicado y del deber de éste de soportar jurídicamente un daño.

\section{Elementos constitutivos de la responsabilidad extracontractual del Estado}

La responsabilidad extracontractual es aquella que surge cuando una persona causa un daño a otra persona, ya sea de manera directa o por medio de otra, a un derecho o un bien patrimonial, de la cual, no existe un vínculo contractual obligatorio anterior al daño causado y surge la obligación de reparar.

Para poder declarar la responsabilidad del Estado o de alguna entidad estatal, debe haberse producido antes una actuación que lesione un derecho imputable a la misma. Esta actuación puede prevenir de un acto, un hecho, una operación, una vía de hecho o una omisión; configurado el daño, surge la responsabilidad administrativa y la obligación de reparar el daño causado. 
Los elementos constitutivos de la responsabilidad extracontractual por parte del Estado son los siguientes:

a.Una actuación de la Administración. Esta actuación puede provenir de actos, hechos, operaciones, vías de hecho $u$ omisiones administrativas, las cuales generan un daño o lesionan un derecho, y que esta actuación sea imputable a la administración.

b. Un daño. El daño es considerado como aquel perjuicio o lesión de un derecho ajeno consistente en el quebranto económico o patrimonial sufrido por la víctima y la lesión al honor o las aflicciones legítimas. El daño producido debe reunir unos requisitos especiales: primero, el daño tiene que ser cierto o real, es decir, que efectivamente haya lesionado un derecho del directamente perjudicado; el daño tiene que ser especial, esto es, que el daño sea particular a la persona o personas que solicitan la reparación; y, por último, el daño tiene que ser anormal, esto es, que debe exceder los inconvenientes inherentes al funcionamiento del servicio y que se refiera a una situación jurídica protegida.

c. El nexo causal. Entre la actuación imputable a la Administración y el daño causado debe existir una relación de causalidad, lo cual quiere decir que el daño debe ser efecto o resultado de aquella actuación.

Regímenes jurídicos o títulos de imputación de la responsabilidad extracontractual del Estado por actos terroristas

Para poder determinar la responsabilidad del Estado, además de los requisitos mencionados anteriormente, es indispensable determinar el título jurídico de imputación, en el cual recae la responsabilidad administrativa que tienen características y formas de aplicación diferentes debido a que en algunos casos se necesita la prueba de la culpa de la autoridad y en otros ésta se presume, o, en algunos eventos de ruptura de la igualdad ante las cargas públicas, la responsabilidad es objetiva. El Consejo de Estado, respecto a los títulos de imputación, estableció lo siguiente: 
Esta Sala, unificó su posición en el sentido de indicar que, en lo que se refiere al derecho de daños, el modelo de responsabilidad estatal que adoptó la Constitución de 1991, no privilegió ningún régimen en particular, sino que dejó en manos del juez definir, frente a cada caso concreto, la construcción de una motivación que consulte las razones tanto fácticas como jurídicas que den sustento a la decisión que habrá de adoptar. Por ello, la jurisdicción de lo contencioso administrativo ha dado cabida a la utilización de diversos "títulos de imputación" para la solución de los casos propuestos a su consideración, sin que esa circunstancia pueda entenderse como la existencia de un mandato que imponga la obligación al juez de utilizar frente a determinadas situaciones fácticas -a manera de recetario- un específico título de imputación.

El uso de tales títulos por parte del juez debe hallarse en consonancia con la realidad probatoria que se le ponga de presente en cada evento, de manera que la solución obtenida consulte realmente los principios constitucionales que rigen la materia de la responsabilidad extracontractual del Estado, tal y como se explicó previamente en esta providencia (Concejo de Estado, 2012, p. 10).

Y en Sentencia C-333 de 1996, la Corte Constitucional manifestó:

El actual mandato constitucional es no sólo imperativo ya que ordena al Estado responder, sino que no establece distinciones según los ámbitos de actuación de las autoridades públicas. En efecto, la norma simplemente establece dos requisitos para que opere la responsabilidad, a saber, que haya un daño antijurídico y que éste sea imputable a una acción u omisión de una autoridad pública.

Por ello, la Corte coincide con el Consejo de Estado en que para imponer al Estado la obligación de reparar un daño "es menester, que además de constatar la antijuricidad del mismo, el juzgador elabore un juicio de imputabilidad que le permita encontrar un 'título jurídico' distinto de la simple causalidad material que legitime la decisión; vale decir, la imputatiojuris además de la imputatiofacti" (República de Colombia, Corte Constitucional, Sentencia C-333, 1996, p. 12). 
Estos sistemas de responsabilidad son en primer lugar la falla en el servicio, la cual es una creación jurisprudencial francesa que fue incorporada en nuestra jurisprudencia contenciosa administrativa y consiste en el quebrantamiento de un contenido obligacional administrativo. En segundo lugar, se encuentra la teoría del riesgo excepcional como fundamento, la cual cobija aquellos casos en los cuales el Estado causa un daño a los particulares en el ejercicio de una actividad riesgosa, sin importar la conducta de quien la causó, por lo cual se encuentra ubicado dentro de los regímenes de responsabilidad objetiva creados por la jurisprudencia, dejando de lado el concepto de la falla del servicio. Por último, la teoría del daño especial consiste en aquel daño que se inflige al administrado en desarrollo de una actuación legítima del Estado, ajustada en un todo a la legalidad pero que debe ser indemnizado por razones de equidad y de justicia distributiva en la medida en que la Administración se ha beneficiado de un daño anormal, desmesurado o superior a aquel que deben sufrir los administrados en razón a la naturaleza particular del poder público, el cual entraña de esta suerte un rompimiento de igualdad ante las cargas del poder público.

\section{Falla del servicio}

La falla del servicio consiste en aquella responsabilidad de carácter subjetivo por parte de Administración con ocasión a la extralimitación de sus funciones por el retardo en el cumplimiento de sus obligaciones, por obligaciones cumplidas tardíamente o de manera defectuosa o por el incumplimiento de las funciones a cargo del Estado. Es decir, la falla del servicio es aquel hecho dañoso causado por la violación del contenido obligacional a cargo del Estado, el cual puede provenir de la Constitución, la ley o el reglamento, que son los que establecen las obligaciones y deberes del Estado y sus servidores.

Esta falla frente a actos terroristas se presenta cuando el daño se produce como consecuencia de la omisión del Estado en la prestación de los servicios de protección y vigilancia, es 
decir, cuando la imputación se refiere a la actuación fallida o irregular de la Administración, que, con conocimiento previo, se comporta con negligencia al no utilizar todos los medios disponibles para repeler, evitar o atenuar el acto terrorista (Ruiz, 2010, p. 11).

Este tipo de responsabilidad se ocasiona cuando el Estado tiene conocimiento acerca de la realización de una amenaza de atentado terrorista y éste omite o no toma las medidas suficientes para evitarlo o contrarrestar esta acción, llevándose a cabo y generando así una serie de daños a los particulares, es decir, hay una falla del servicio de vigilancia por parte del Estado por no brindar la protección necesaria o porque, habiendo situaciones particulares de alteración del orden público, no brinden la protección requerida o lo hagan de manera insuficiente.

La Sección Tercera, en sentencia del Consejo de Estado del 23 de septiembre de 1994, estableció lo siguiente:

Resulta claro que, no obstante las advertencias formuladas por las directivas del D.A.S., en relación con la necesidad de poner en práctica controles estrictos para proteger la sede de la institución -que, conforme a las informaciones obtenidas y dada la situación de violencia en que se encontraba el país, y especialmente el atentado que se había producido seis meses antes contra su director, el General Miguel Maza Márquez, se encontraba gravemente amenazada-, el carro que tenía la carga de dinamita con la que se perpetró el atentado del 6 de diciembre de 1989 llegó hasta la calle 17A, ubicada en las proximidades del edificio. Así las cosas y teniendo en cuenta, además, que dicha carga era aproximadamente de 800 kilos, como lo expresa el propio apoderado de la demandada, no cabe duda de que tales controles no fueron efectuados con la diligencia debida. Se ha visto, adicionalmente, que varias dependencias el D.A.S. tenían a su cargo el deber concreto de proteger las instalaciones de la entidad, y a ellas se impartieron las instrucciones respectivas, que, sin duda alguna, teniendo en cuenta los resultados anotados, fueron claramente desatendidas, y es evidente que, de no haber sido así, se habría impedido el ingreso del carro-bomba a la calle mencionada y, por lo tanto, la realización del atentado y sus funestas consecuencias. 
Por lo anterior, reiterando la postura adoptada por esta Sala en otros procesos referidos a los mismos hechos, se considera que el daño causado, en el presente caso, resulta imputable a la Nación -Departamento Administrativo de Seguridad- D.A.S. (República de Colombia, Concejo de Estado, 1994).

En este tipo de responsabilidad, el accionante debe demostrar que, en efecto, existían una serie de sucesos concadenados que le permitían a las autoridades estatales deducir la inminencia de un ataque terrorista y que la Administración no realizó las acciones tendientes a evitarlo. Para determinar si la conducta del Estado fue anómala o irregular, por acción $\mathrm{u}$ omisión, frente al hecho dañoso perpetrado por el tercero debe analizarse si para la Administración y para las autoridades era previsible que se desencadenara el acto terrorista.

Para que el Estado pueda exonerar su responsabilidad debe demostrar que, aunque el hecho fue causado, es imputable a éste; que el Estado obró de manera prudente y con tal diligencia que su actuación no puede calificarse como omisiva, imprudente o negligente en forma tal que dé lugar a comprometer su responsabilidad. Igualmente, no existirá responsabilidad por falla en el servicio en aquellos casos en los cuales el atentado solo se trató de causar pánico a la colectividad, es decir, en aquellos casos en donde el ataque no fue selectivo, en donde no hay objetos o sujetos representativos del Estado, requisito indispensable para determinar la responsabilidad del Estado.

La Sección Tercera del Consejo de Estado, en sentencia del 8 de febrero de 1999, estableció lo siguiente:

Dado que en relación con el hecho no se aportó ninguna prueba diferente al testimonio del señor Navarro Lizarazo y que éste ni presenció el hecho, pues fue obligado a ocultarse en una alcantarilla, ni tiene conocimiento de los móviles ni de los autores del mismo, y por lo tanto no está acreditado que el hecho constituyó un acto terrorista dirigido contra un objetivo representativo del Estado, forzoso es concluir que no se dan los presupuestos para proferir una condena por daño especial. Tampoco podrá condenarse al Estado por falla del servicio porque no se demostró que el día de los hechos se hubiera presentado en el área una situación de perturbación del orden público que demandara una 
especial vigilancia del Estado, tampoco se acreditó que el actor hubiera requerido de las autoridades una mayor protección con anterioridad a la ocurrencia del hecho ni que las autoridades hubieran desatendido su deber de prever y controlar el hecho, pues sólo tuvieron conocimiento del mismo con posterioridad a su ejecución (República de Colombia, Consejo de Estado, 1999).

Por último, hay que resaltar que la responsabilidad por falla del servicio en los casos de actos o hechos terroristas es el título de imputación más común mediante el cual el juez contencioso administrativo fundamenta la responsabilidad administrativa del Estado.

\section{Riesgo excepcional}

La responsabilidad del Estado por este título de imputación surge cuando éste crea un riesgo que excede la igualdad ante las cargas públicas que normalmente deben soportar los ciudadanos, es decir, es un riesgo excepcional en la medida en que se expone a una persona o a un grupo particular de personas a un peligro como consecuencia del desarrollo de una actividad dirigida a proteger a la comunidad en general. A diferencia de la falla en el servicio, ésta no se trata de la existencia de una acción o una omisión imputable al Estado y sus autoridades, sino de la producción de un daño que, si bien es causado por un tercero, surge de la realización de un riesgo excepcional creado por la Administración en cumplimiento de sus deberes.

La teoría del riesgo excepcional se da cuando el Estado compromete su responsabilidad cuando quiera que en la construcción de una obra o en la prestación de un servicio, desarrollados en beneficio de la comunidad, emplea medios o utiliza recursos que colocan a los administrados, bien en sus personas o en sus patrimonios, en situación de quedar expuestos a experimentar un 'riesgo de naturaleza excepcional' que, dada su particular gravedad, excede notoriamente las cargas que normalmente han de soportar los administrados como contrapartida de los beneficios que derivan de la ejecución de la obra o de la prestación del servicio (República de Colombia, Consejo de Estado, 1989, p. 32) 
El Consejo de Estado, en sentencia de 10 de agosto de 2000, manifestó lo siguiente:

Que la imputabilidad surge de la creación de un riesgo que es considerado excepcional, en la medida que se supone la puesta en peligro de un grupo particular de ciudadanos, como consecuencia del desarrollo de una actividad lícita dirigida a proteger a la comunidad en general. No se trata aquí, de una acción $u$ omisión de la administración, sino de la protección de un daño que, si bien es causado por un tercero, surge de la realización de un riesgo excepcional, creado conscientemente por el Estado en cumplimiento de sus funciones, y es la excepcionalidad del riesgo lo que hace la ruptura del equilibrio frente a las cargas públicas y posibilita el surgimiento de la responsabilidad patrimonial del Estado (República de Colombia, Concejo de Estado, 2000, p. 22).

Esta teoría se aplica a los actos terroristas cuando hay ataques dirigidos a elementos representativos del Estado, funcionarios estratégicos del mismo, colocando a los particulares en una situación de riesgo creado de manera consciente por el Estado que se torna excepcional y que, en caso de realizarse y causarse un daño, desborda los parámetros bajo los cuales está desarrollado el principio de igualdad frente a las cargas públicas.

En efecto, si bien ha sido reiterada la jurisprudencia extranjera, y fundamentalmente la francesa y la española, en el sentido de expresar que el Estado no asume responsabilidad patrimonial alguna por éste tipo de actos incluidos dentro de las denominadas operaciones de guerra, esta Sala se ha apartado de aquéllas, al considerar que, dadas las circunstancias en que los mismos se producen, podrían resultar imputables a una acción u omisión de la administración, que bien puede consistir en una falla del servicio, o en la exposición de algunas personas a un riesgo excepcional, creado en cumplimiento del deber constitucional y legal del Estado de proteger a la comunidad en general.

En otros eventos, como se vio, la imputabilidad surge de la creación de un riesgo, que es considerado excepcional, en la medida en que supone la puesta en peligro de un grupo particular de ciudadanos, como consecuencia del desarrollo de una actividad dirigida a proteger a la comunidad en general. 
No se trata aquí, entonces, de la existencia de una acción u omisión reprochable de la administración, sino de la producción de un daño que, si bien es causado por un tercero, surge por la realización de un riesgo excepcional, creado conscientemente por ésta, en cumplimiento de sus funciones. Y es la excepcionalidad del riesgo lo que hace evidente la ruptura del equilibrio frente a las cargas públicas y posibilita el surgimiento de la responsabilidad patrimonial del Estado (República de Colombia, Consejo de Estado, 2000, p. 19).

Para que se establezca esta teoría, el ataque terrorista debe ser sorpresivo y debe estar dirigido contra un elemento representativo del Estado o contra un alto funcionario y causar daños a terceros. Como lo señaló el Consejo de Estado de la siguiente manera:

Sobre el fundamento del riesgo excepcional, "Ese desequilibrio de las cargas públicas traducido en el riesgo excepcional a que se sometió a los actores y cuya concreción, es decir, el daño, no están en el deber jurídico de soportar, obliga a su restablecimiento a través de la indemnización. Una prueba fehaciente del estado de peligro es su propia realización como sucedió en el presente caso, en donde el temor permanente que soportaron los actores de que se atentara contra el "CAI" vecino, efectivamente se convirtió en una realidad al ser blanco de una explosión dinamitera que, afortunadamente, no produjo pérdida de vidas, pero sí otros daños. Precisa la Sala, que el peligro no cesó porque el día en que se produjo el atentado el "CAI" ya no estuviese en servicio, porque la Policía Nacional lo había desocupado; éste hecho no eliminó el riesgo al que estaban sometidos los actores, puesto que la ola terrorista desatada, a gran escala, contra establecimientos de la Policía Nacional, como los Comandos de Atención Inmediata, no hacía distinción entre aquellos que se encontraban en funcionamiento de los que no lo estaban, como ocurrió en el caso sub judice, bastó la sola existencia de sus instalaciones para que la delincuencia organizada lo convirtiera en objeto directo de su acción delictiva.” Éste fundamento fue ratificado posteriormente (república de Colombia, Consejo de Estado, 2002).

Los elementos estructurales de la responsabilidad por riesgo excepcional son: 
a. Un riesgo de naturaleza excepcional para los administrados que aparece por la amenaza potencial contra los elementos de acción del Estado.

b. Un daño generado a una persona o grupos de personas particulares.

c. El nexo de causalidad entre el daño y la conducta de riesgo creada por el Estado.

En sentencia del 19 de abril de 2012, el Consejo de Estado estableció lo siguiente frente a los elementos estructurales:

RESPONSABILIDAD POR RIESGO EXCEPCIONAL cuando en un actuar legítimo la autoridad coloca en riesgo a unas personas en aras de proteger a la comunidad. La Sala ha precisado que los elementos estructurales de la responsabilidad bajo este título jurídico, son: "Un riesgo de naturaleza excepcional para los administrados que aparece por la amenaza potencial contra los instrumentos de acción del Estado -instrumentales, humanos y de actividad- en época de desórdenes públicos provenientes y propiciados por terceros que luchan contra el mismo Estado y que se concreta con el ataque real de esos instrumentos y la consecuencia refleja en los administrados (personas o bienes), que quebranta la igualdad frente a las cargas públicas. El daño a bienes protegidos por el derecho. El nexo de causalidad, entre el daño y la conducta de riesgo creada por el Estado, con eficiencia de producir aquel.

La responsabilidad patrimonial del Estado se ve comprometida cuando en ejercicio de sus actividades y obrando dentro del marco de las disposiciones legales, utiliza recursos o medios que colocan a los particulares o a sus bienes en situación de quedar expuestos a un riesgo de naturaleza excepcional; éste, dada su gravedad, excede las cargas normales que deben soportar los particulares como contrapartida de las ventajas que resulta de la existencia de dicho servicio público. La Sala no desconoce que el daño en sí mismo considerado no lo produjo el Estado, sino que lo produjo un tercero, pero advierte que para su producción del riesgo sí fue eficiente en el aparecimiento del mismo (República de Colombia, Consejo de Estado, 2001).

Ésta es considerada como un tipo de responsabilidad objetiva, en la cual el demandante no está obligado a probar la culpa de la Administración y a la Administración de controvertirla, 
ya que al Estado solo se exonerará su responsabilidad demostrando la existencia de una causa extraña que rompa el nexo de causalidad.

En conclusión, se puede establecer que en materia de responsabilidad del Estado mediante el título de imputación de responsabilidad objetiva del riesgo excepcional por actos terroristas, el Consejo de Estado y la doctrina ha determinado que éste se da cuando el Estado realiza una actividad lícita como la construcción de un CAI o Comando, los cuales en sí no son una actividad peligrosa, pero que sí crea con posterioridad un riesgo anormal para quienes están alrededor en vista de que los bienes o las personas de las que se trata constituyen objetivos militares en la guerra interna que se vive en Colombia.

\section{Daño especial}

Según la jurisprudencia del Consejo de Estado, se está frente a este daño cuando el Estado en su actuar legítimo y en beneficio de la comunidad causa un daño especial, anormal y superior al que normalmente deben soportar los gobernados en contraprestación del servicio prestado (República de Colombia, Consejo de Estado, 1973). Es decir, en el daño especial, la actividad que ejecuta el Estado no resulta ser peligrosa, a diferencia del riesgo excepcional donde la actividad que ejecuta la Administración pone en situación de riesgo al particular, la cual se ejerce en provecho o en beneficio suyo y le impone una carga que no está en el deber jurídico de soportar.

En el daño especial, la actividad lícita que ejerce el Estado rompe con el principio de igualdad frente a las cargas públicas $y$, por tal, vulneran los derechos de los particulares.

El Consejo de Estado, a través de su Sección Tercera, en sentencia del 27 de noviembre de 2003, frente a la teoría del daño especial, manifestó lo siguiente.

Como quedó expuesto, para la Sala en esa oportunidad, el asunto sometido a su conocimiento podía resolverse, bien, con fundamento en la teoría del riesgo, bien con fundamento en la falla del servicio al no adoptar las medidas de protección necesarias o aún con fundamento en la teoría del daño especial. 
Como se ha sostenido en otras oportunidades, ha existido confusión, tanto en la jurisprudencia como en la doctrina, frente a los regímenes del daño especial y el riesgo excepcional, pues, bajo las dos orientaciones la actividad desarrollada por la Administración es lícita; ésta se ejerce en cumplimiento de un deber legal y se aplica con fundamento en el rompimiento del principio de igualdad de las personas frente a las cargas públicas, en el daño especial la actividad no resulta ser peligrosa, en cambio, en la teoría del riesgo excepcional, la actividad de la Administración es la que coloca en situación de riesgo al individuo, la cual se ejerce en provecho o en beneficio suyo y le impone a los asociados una carga que no tienen por qué soportar. De tal modo que, en este último caso, el fundamento de la responsabilidad descansa sobre el hecho de que el daño sufrido surge de la actividad riesgosa creada por el Estado, la que sin duda resulta imputable a la administración; en cambio, en el daño especial, la actividad lícita ejercida por la administración rompe con el principio de igualdad frente a las cargas públicas y lesiona los intereses del administrado. (República de Colombia, Consejo de Estado, 2003).

Igualmente, en sentencia del 23 de septiembre de 2012, el Consejo de Estado estableció lo siguiente:

Como sea que los hechos que dieron lugar al daño por el cual hoy se reclama ocurrieron en el marco del conflicto armado interno y resulta evidente que es al Estado a quien corresponde la búsqueda de soluciones que conlleven a la terminación de la guerra, de ahí que debe convenirse en que se aparta de los más elementales criterios de justicia y equidad que al producirse estos ataques subversivos, el Estado no acuda a socorrer a sus víctimas.

Ahora, en cuanto al título de imputación como herramienta de motivación que debe ser aplicado para dar respuesta al caso concreto, la Sala considera que, en aras de materializar el valor justicia, la responsabilidad del Estado en este caso se ha comprometido a título de daño especial, por entenderse que no hay conducta alguna que pueda reprochársele a entidad demandada, quien actuó dentro del marco de sus posibilidades, así como tampoco se puede reprochar la conducta de la actora, quien se presenta como habitante del pequeño poblado de Silvia, víctima indirecta de un ataque dirigido contra el Estado, cuyo 
radio de acción no se limitó a objetivos estrictamente militares, sino que comprendió también a la población civil y que, en tales circunstancias le causó un perjuicio en un bien inmueble de su propiedad, trayendo para ella un rompimiento de las cargas públicas que debe ser indemnizado. En conclusión, la Sección considera que en este caso resulta aplicable la teoría del daño especial, habida cuenta que el daño, pese que se causó por un tercero, lo cierto es que ocurrió dentro de la ya larga confrontación que el Estado ha venido sosteniendo con grupos subversivos, óptica bajo la cual, no resulta constitucionalmente aceptable que el Estado deje abandonadas a las víctimas y, que explica que la imputación de responsabilidad no obedezca a la existencia de conducta alguna que configure falla en el servicio, sino que se concreta como una forma de materializar los postulados que precisamente justifican esa lucha contra la subversión y representan y hacen visible y palpable, la legitimidad del Estado (República de Colombia, Consejo de Estado, 2012).

Para evitar confusión en la aplicación del título de imputación del daño especial frente al de del riesgo excepcional, el Consejo de Estado ha establecido una serie de requisitos o características esenciales para que pueda aplicarse la figura de daño especial; estos son:

a. Que se desarrolle una actividad legítima de la Administración;

b. La actividad debe tener como consecuencia el menoscabo del derecho de una persona;

c. El menoscabo del derecho debe tener origen en el rompimiento del principio de la igualdad frente a la Ley y a las cargas públicas;

d. El rompimiento de esa igualdad debe causar un daño grave y especial, en cuanto recae sólo sobre alguno o algunos de los administrados;

e. Debe existir un nexo causal entre la actividad legítima de la Administración y el daño causado; y

f. El caso concreto no puede ser susceptible de ser encasillado dentro de otro de los regímenes de responsabilidad de la Administración. 
De lo anterior, se puede establecer que éste es un título que sólo se aplica de manera subsidiaria, es decir, sólo se recurre a él en el evento de no lograr enmarcar el caso en otro título, fundamentado éste en la reparación del daño causado por el de principio de igualdad ante las cargas públicas. El Estado, para eximirse de la responsabilidad que se le imputa, puede probar el rompimiento del nexo causal por medio de cualquiera de las siguientes causales:

a. Caso fortuito (República de Colombia, Consejo de Estado, 1976): consistente en el acontecimiento imprevisible e irresistible pero que acontece o se produce dentro del campo propio de la actividad administrativa, del actuar del agente. Es, pues, esencialmente interno a la actividad.

b. Fuerza mayor: es el suceso externo a la actividad de la administración, imprevisible, es decir, no hay manera de sospechar la ocurrencia del hecho dañino e irresistible, o sea, aquel de tal entidad que es imposible contrarrestar.

c. Hecho de un tercero: aquí el origen o la razón del daño emanan de la culpa de un tercero, de una persona, único responsable de lo sucedido. Es necesario que el daño haya sido provocado exclusivamente por la acción de ese tercero, si no es así, no se configurará esta causal exonerativa.

d. Hecho exclusivo de la víctima: el hecho de la víctima puede ser considerado como causal excluyente de responsabilidad si se prueba, no sólo que la víctima participó en la realización del daño, sino que entre su actuación y el daño existe hay una relación de causalidad adecuada, entendida ésta como aquella causa idónea, eficiente y preponderante cuya consecuencia directa e inmediata es el daño mismo.

e. Inexistencia de un daño antijurídico: para que pueda existir una reparación debe existir un daño, el cual tiene que ser cierto, que efectivamente haya lesionado un derecho del directamente perjudicado, y el daño tiene que ser especial, anormal y que se refiera a una situación jurídica protegida. 


\section{CONCLUSIONES}

Del análisis anterior, se puede concluir y afirmar que si bien existen en Colombia algunas normas o legislación en materia de indemnización frente a las víctimas de atentados terroristas, brindando a éstas una compensación económica, sigue siendo la jurisdicción contenciosa administrativa, la vía por la que las víctimas acuden para recibir una reparación integral de los daños ocasionados por los actos terroristas cuando su responsabilidad es atribuible al Estado por acción u omisión.

Es así como con la constitucionalización de la responsabilidad del Estado, en el artículo 90 de la Constitución Política colombiana y de las importantes evoluciones jurisprudenciales del Consejo de Estado y Corte Constitucional se logra establecer un régimen de responsabilidad extracontractual del Estado frente a los actos terroristas.

De esta manera, se puede determinar que la responsabilidad extracontractual del Estado por actos terroristas ha sido encasillada en el régimen de responsabilidad objetiva por la jurisprudencia del Consejo de Estado, muy a pesar de que la falla en servicio es el título de imputación más común por el cual es demandado el Estado frente a este tipo de actos.

Por otra parte, la falla del servicio en la jurisprudencia del contencioso administrativo ha adoptado una concepción del terrorismo de manera global, es decir, sea que el acto cometido haya sido realizado por terroristas ocasionales o terroristas propiamente dichos, siempre y cuando se logre probar la conducta omisiva de la Administración, ésta es responsable por los daños ocasionados. En otras palabras, esta falla en la asistencia se da cuando el daño se produce como consecuencia de la omisión del Estado en la prestación de los servicios de protección y vigilancia al no utilizar todos los medios que tuviera a su alcance para repeler, evitar o atenuar un acto o atentado terrorista, aun teniendo conocimiento previo sobre los hechos. 
Sin embargo, para los títulos de imputación de responsabilidad objetiva, el Consejo de Estado en sus múltiples sentencias ha establecido que esta responsabilidad deviene de aquel rompimiento de la igualdad de las cargas públicas en el actuar legítimo del Estado, el cual genera un riesgo traducido en un daño ocasionado por un acto terrorista. En estos eventos, la acción terrorista no necesariamente tiene que ir dirigido al Estado o a un elemento representativo de éste, ya que se ha de presumir que todo evento terrorista va dirigido contra éste; entonces, cuando el juez no encuentra probados los elementos de la falla del servicio, debe estudiar la posibilidad de que los perjuicios se hayan producido por un atentado que constituya la concreción de un riesgo creado por la Administración de forma lícita. Si encuentra prueba lo anterior, el Estado debe responder por el riesgo excepcional.

Para finalizar este artículo, se determina que el daño especial se puede establecer, según el Consejo de Estado, como un valor y un carácter subsidiario frente a los dos anteriores, es decir, sólo se recurre a él en el evento de no lograr enmarcar el caso en otro título. Se fundamenta éste en la reparación del daño causado por el principio de igualdad ante las cargas públicas.

\section{REFERENCIAS}

Comité Internacional de la Cruz Roja - CICR, (2011). Derecho Internacional y terrorismo, respuestas a preguntas clave. Recuperado de: https://www.icrc.org/spa/resources/documents/faq/5yyqg4.htm\#Questableceelderechointernacional humanitariosobreelterrorismo

elespectador.com. (2017). El Espectador. Redacción Nacional. Judicial. Recuperado el 4 de julio de 2017 de: http://www.elespectador.com/noticias/judicial/capturan-tres-presuntosintegrantes-del-clan-del-golfo-en-uraba-articulo-701405

República de Colombia. Código Civil. (15 de abril de 1887). Artículo 2341. [Ley 57]. Recuperado de https://www.oas.org/dil/ esp/codigo_Civil_Colombia.pdf 
Hernández, A. E. (2001). Evolución jurisprudencial de la responsabilidad del Estado por daños causados por actos terroristas. Revista del Instituto Antioqueño de Responsabilidad Civil y del Estado, (11).

República de Colombia. Corte Constitucional. (1 de agosto de 1996). Sentencia C-333. Norma acusada: Artículo 50 (parcial) de la Ley 80 de 1993. [MP: Alejandro Martínez Caballero].

República de Colombia. Consejo de Estado. (29 de Julio de 1947). Sentencia El siglo S.A. Anales del Consejo de Estado. [MP: Gustavo Valbuena].

República de Colombia. Consejo de Estado. Sección Tercera. (23 de mayo de 1973). Sentencia 978. Responsabilidad del Estado por actos terroristas. [MP: Alfonso Castilla Saiz].

República de Colombia. Consejo de Estado. Sección Tercera. (20 de Febrero de 1989). Sentencia 4655. Demanda-Requisitos / Principio de congruencia / Jura novit curia / Accion de reparacion directa y cumplimiento. [MP: Antonio Jose De Irisarri Restrepo].

República de Colombia. Consejo de Estado. Sección Tercera. (23 de septiembre de 1994). Sentencia 8577. Perjuicios por atentados terroristas y responsabilidad por daño especial. [MP: Julio César Uribe Acosta].

República de Colombia. Consejo de Estado. Sección Tercera. (8 de febrero de 1999). Sentencia 10.731. Responsabilidad estatal por atentados terroristas al servicio de transporte. [MP: Ricardo Hoyos Duque].

República de Colombia. Consejo de Estado. Sección Tercera. (10 de agosto de 2000). Sentencia 11.585. Circunstancias en que existe responsabilidad del estado en actos terroristas. [MP: Alier Eduardo Hernández].

República de Colombia. Consejo de Estado. Sección Tercera. (19 de abril de 2012). Sentencia 1999-00815/21515. Responsabilidad del Estado por destrucción de inmuebles. [MP: Hernán Andrade Rincón].

Ruiz, W. (2010). Responsabilidad del Estado y sus regímenes. Bogotá, D.C.: Ecoediciones. 
EVOLUCIÓN JURÍDICA DE LA RESPONSABILIDAD DEL

ESTADO POR ACTOS TERRORISTAS EN COLOMBIA

Tamayo, J. (2000). La responsabilidad del Estado. Bogotá, D.C.: Temis. 